\title{
PENGEMBANGAN SUMBER DAYA MANUSIA (SDM) DALAM BIDANG AGAMA DAN SOSIAL KEMASYARAKATAN DI KAMPUNG KAWUNG LUWUK
}

\author{
Mohamad Sahril ${ }^{1}$, M. Lucky Setiawan, Rahma Oktafiana Rani ${ }^{2}$ \\ msahril@uika-bogor.ac.id \\ Dosen Fakultas Keguruan dan Ilmu Pendidikan ${ }^{1}$, Mahasiswa KKN Kelompok 68 Tahun \\ $2018^{2}$
}

\begin{abstract}
ABSTRAK
Kuliah Kerja Nyata (KKN) merupakan satu dari tiga elemen Tri Dharma perguruan tinggi, yakni Pengajaran, Penelitian dan Pengabdian kepada masyarakat. Ini menjadi tugas yang harus dijalankan oleh civitas akademika baik mahasiswa maupun dosen. Secara subtansi, KKN menjadi media bag mahasiswa untuk melakukan pengabdian kepada masyarakat secara langsung di lapangan. Disinilah proses pembelajaran mahasiswa melalui berbagai kegiatan langsung di tengah-tengah masyarakat dilakukan. Dalam tugas ini, kelompok mahasiswa melakukan observasi dengan metode tanya jawab dengan masyarakat dan pendokumentasian. Berdasarkan hasil observasi ditentukanlah program kerja yang meliputi program fisik dan non fisik. Adapun program fisik yaitu kerja bakti kampung, posterisasi, pendataan penduduk, uriuri permainan tradisional, perbaikan dan pengembangan TBM dan pengembangan apotek hidup. Sedangkan program nonfisik yaitu penyuluhan dan pemeriksaan kesehatan, pendampingan PAUD, bimbingan belajar, pelatihan hasta karya, senam sehat kampung mingguan, serta penutupan. Dalam menjalankan program-program tersebut, mahasiswa berperan sebagai fasilitator, dinamisator dan motivator. Pelaksanaan program kerja yang dimulai dari tanggal 07 Agustus 2018-05 September 2018.
\end{abstract}

\section{Kata kunci : Keagamaan, sosial kemasyarakatan.}

\section{PENDAHULUAN}

Kampung Kawung Luwuk merupakan bagian dari Desa Sibanteng Kecamatan Leuwisadeng Kabupaten Bogor, Jawa Barat. Sebagian pemukiman terletak di bahu jalan dan sebagian terletak di dekat area persawahan. Lokasi pemukiman di Kampung Kawung Luwuk terbilang cukup padat. Sudah tersebarnya instansi kependidikan. Tersedia pula masjid serta pos ronda. Desa Sibanteng perbatasan desa. Di sebelah Barat Desa Sadeng, di sebelah Timur dibatasi
Leuwisadeng.Sebelah Utara berbatasan dengan Desa Rumpin/Cigudeg sebelah Selatan dengan Luewisadeng.

Desa Sibanteng memiliki luas areal $\pm 641.000,000$ ha. Total penduduk di Desa Sibanteng 9.550. buruh tani sebanyak 450 orang, buruh industri 120 orang, buruh bangunan sebanyak 645 orang, buruh pertambangan 15 orang, pedagang 244 orang, pengemudi 145 orang, pegawai negeri sipil 312 orang, tni polri 31 orang.

Kp. Kawung Luwuk merupakan salah satu wilayah Desa Sibanteng yang tergolong padat penduduk. Dapat dilihat 
dari kuantitas rumah serta letak dari satu rumah ke rumah lainnya. Kondisi seperti ini sangat mempengaruhi keadaan sosial di masyarakat setempat. Kondisi masyarakat yang individual dan berkubu begitu terlihat jelas. Didukung dengan demografi wilayah yang terletak di lintas jalan raya.

\section{METODE PENGABDIAN}

Tahapan pelaksanaan untuk kegiatan ini sebagaimana terlihat pada bagan sebagai berikut:

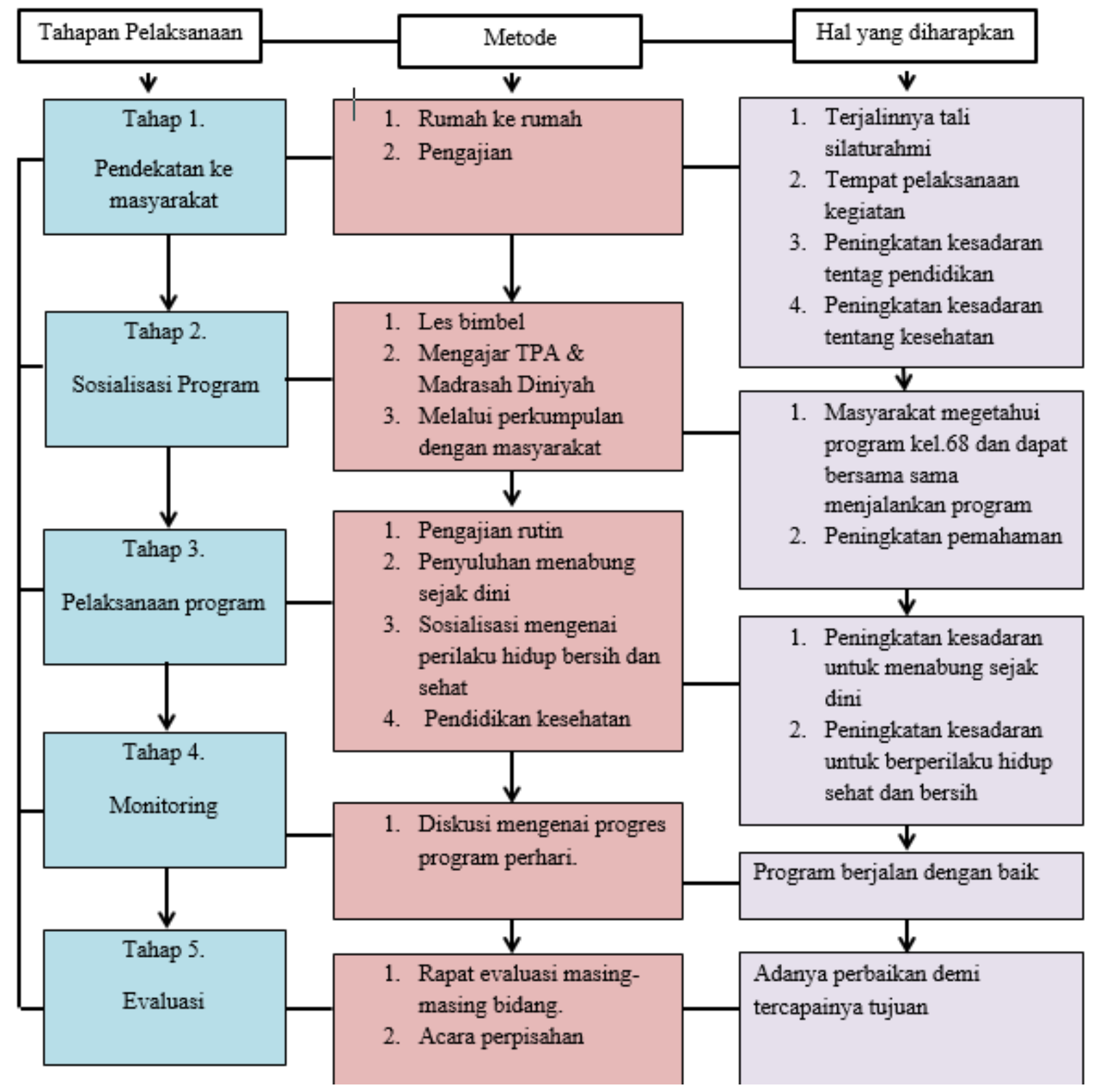




\section{Jadwal Kegiatan}

\begin{tabular}{|c|c|c|c|c|c|}
\hline \multirow[t]{2}{*}{ No } & \multirow[t]{2}{*}{ Kegitan } & \multicolumn{4}{|c|}{ Minggu } \\
\hline & & 1 & 2 & 3 & 4 \\
\hline 1 & $\begin{array}{l}\text { Penyuluhan PHBS ke SD (Perilaku } \\
\text { Hidup Bersih Dan Sehat) }\end{array}$ & & & $\sqrt{ }$ & \\
\hline 2 & Demo Cara Cuci Tangan yang baik & & & $\sqrt{ }$ & \\
\hline 3 & Cek kesehatan (Tensi Darah) & & & $\sqrt{ }$ & \\
\hline 4 & Senam Hipertensi & & $\sqrt{ }$ & & \\
\hline 5 & Pengajaran PAUD & $\sqrt{ }$ & & & \\
\hline 6 & $\begin{array}{l}\text { Pengajaran TPA (Taman } \\
\text { Pendidikan Al - Quran) }\end{array}$ & $\sqrt{ }$ & & & \\
\hline 7 & Pemberian Bimbingan Belajar & $\sqrt{ }$ & & & \\
\hline 8 & $\begin{array}{l}\text { Penayangan Film Pendidikan dan } \\
\text { Motivasi }\end{array}$ & & $\sqrt{ }$ & & \\
\hline 9 & $\begin{array}{l}\text { Sosialisasi tentang akan pentingnya } \\
\text { menabung diusia dini, pembagian } \\
\text { celengan dan menghias celengan. }\end{array}$ & & & $\sqrt{ }$ & \\
\hline 10 & Pembuatan papan nama jalan & & & $\sqrt{ }$ & \\
\hline 11 & Renovasi pos kamling & & & & $\sqrt{ }$ \\
\hline 12 & Pengajian (ibu,anak,dan bapak) & & $\sqrt{ }$ & & \\
\hline 13 & $\begin{array}{l}\text { Memberikan Pengadaan } \\
\text { Perlengkapan Peribadatan }\end{array}$ & & & & $\sqrt{ }$ \\
\hline 14 & Kaderisasi Baca Tulis Al-Qur'an & & $\sqrt{ }$ & & \\
\hline 15 & Bazar pakaian murah & & & & $\sqrt{ }$ \\
\hline
\end{tabular}




\section{Metode Pendekatan}

Pendekatan yang digunakan dalam kegiatan ini adalah:

1. Pendekatan Religius metode ini kami menggunakan metode pendekatan religi dalam pelaksanaan program $\mathrm{kkn}$ ini khususnya bidang pendidikan. semua ini dilatar belakangi oleh situasi lingkungan dimana masyarakat sekitar masih menjungjung tinggi nilai agama dalam kehidupan. Sehingga dalam pelaksanaannya semua materi pendidikan berhubungan dengan religi. Seperti mengajar ngaji, mengajarkan ilmu-ilmu tajwid, mengajarkan tata cara beribadah yang baik dan benar, dan mengajarkan doa sehari-hari kepada anak-anak di TPA maupun di Madrasah Diniyah. Disamping pengajaran untuk anak- anak, kami mengadakan pengajian untuk para pemuda pemudi sekitar dengan tujuan untuk memberikan ilmu pengetahuan ilmu agama yang kami miliki, seperti tausiyah dengan materi " berlombalomba dalam menuju kebaikan”, agar para pemuda pemudi mendapatkan pengetahuan dan wawasan baru dalam ilmu agama. Selain itu kami pun menyisipkan motivasi kepada mereka bahwa pendidikan di sekolah juga penting untuk kehidupan mereka dimasa yang akan dating.

2. Pendekatan Sistem yaitu pendekatan yang dilaksanakan oleh tim dalam melaksanakan program kepada masyarakat. Tim perlu mempunyai dan menerapkan wawasan bersistem, bahwa untuk mewujudkan visi program itu diperlukan cara-cara tentang mendayagunakan semua sumber yang ada dan bila perlu harus diadakan olehnya agar interaksi dengan masyarakat berlangsung dengan aktif lancar dan akhirnya menghasilkan kompetensi yang telah ditentukan.

3. Pendekatan Berdasarkan Karakter Masyarakat Pendekatan berdasarkan karakter masyarakat, yaitu dimana pembinaan yang dilakukan akan disesuaikan dengan karakter masyarakat setempat. Sehingga dalam pelaksanaannya kita memberikan contoh langsung agar hasil yang didapatkan bersifat riil sesuai keadaan yang berkembang dimasyarakat. Walaupun dalam semua aspek pelaksanaanya tidak berjalan sesuai dengan program kegiatan. Masyarakat mampu menerima dan merespon apa yang kita berikan itu sudah termasuk hal positif bagi kami dalam menjalankan program kegiatan. Pendekatan kekerabatan, artinya bahwa pembinaan yang dilakukan senantiasa dikaitkan dalam rangka membangun kekerabatan antar masyarakat.

\section{Partisipasi Masyarakat dalam \\ Pelaksanaan Program}

Partisipasi masyarakat dilakukan dalam kegiatan yang kami selenggarakan adalah sebagai berikut:

1. Mempersiapkan partisipan yang bersedia mengikuti penyuluhan serta program-program yang melibatkan masa.

2. Mempersiapkan sarana serta prasara yang dibutuhkan selama program berjalan. Selebihnya kami kerjakan sendiri karena masyarakat disana memiliki kesibukan masingmasing dan kami tidak bisa mengganggu aktivitas mereka yang memang sudah biasa mereka lakukan.

3. Masyarakat dari anak-anak yang bersedia mengikuti pembinaan baik 
program pendidikan dan mempersiapkan tempat untuk pembinaan dan pelatihan.

4. Pelaksanaan kegiatan pembinaan, terutama tentang pendidikan tambahan yaitu pendidikan non formal seperti les, Taman Pendidikan Al-Qur'an.

5. Melakukan monitoring pelaksanaan pembinaan dan pelatihan untuk masyarakat.

\section{Langkah Evaluasi} terdiri dari:

Evaluasi yang akan dilakukan

1. Evaluasi proses, yang terkait dengan perencanaan, pelaksanaan dan monitoring kegiatan.

2. Evaluasi proses dilakukan setiap pekan bersama dengan masyarakat.

3. Evaluasi hasil, yang dilaksanakan setelah kegiatan dilaksanakan.

4. Evaluasi hasil ditujukan untuk menguji pemahaman masyarakat tentang pentingnya pendidikan.

5. Evaluasi dampak, yang dilakukan.

6. Evaluasi proses, yang terkait dengan perencanaan dan pelaksanaan. Evaluasi proses dilakukan setiap hari bersama tim di masing-masing bidang.

7. Evaluasi hasil, yang dilaksanakan setelah kegiatan dilaksanakan. Evaluasi hasil ditujukan untuk menilai keberhasilan program yang telah dilaksankan serta penentuan keberlanjutan ke program berikutnya.

8. Evaluasi dampak, dilakukan di penghujung masa kerja setelah pelaksanaan program berlangsung. Evaluasi dampak dilakukan sebagai upaya penilai akhir keberhasilan program yang diterapkan.

\section{REALISASI PROGRAM}

\section{Program Bidang Kesehatan}

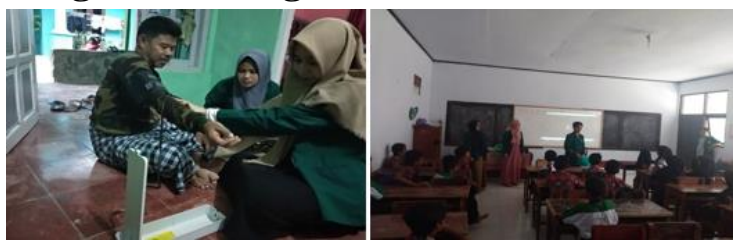

a. Sosilisasi Pendidikan Kesehatan Masyarakat (Tensi Darah Gratis dan PHBS)

\section{Program Bidang Ekonomi}

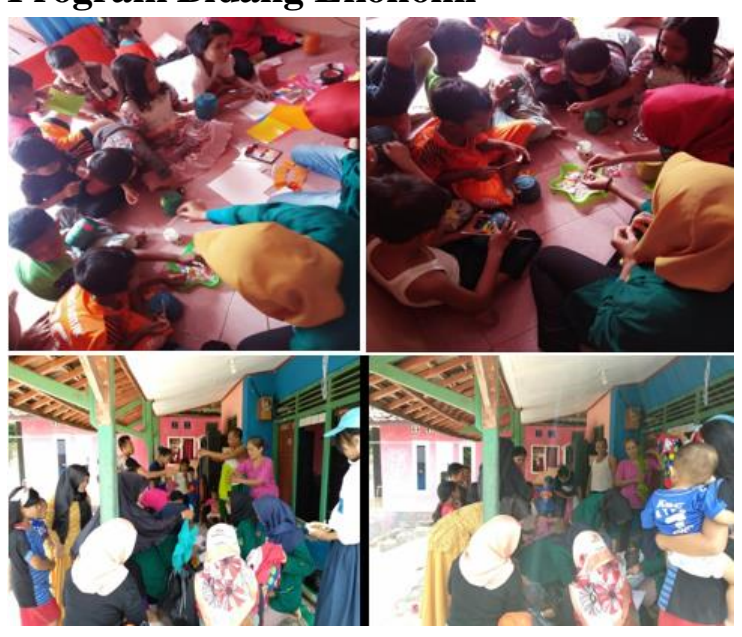

a. Sosialisasi tentang pentingnya menabung di usia dini.

b. Mengadakan bazar pakaian murah.

\section{Program Bidang Pendidikan}

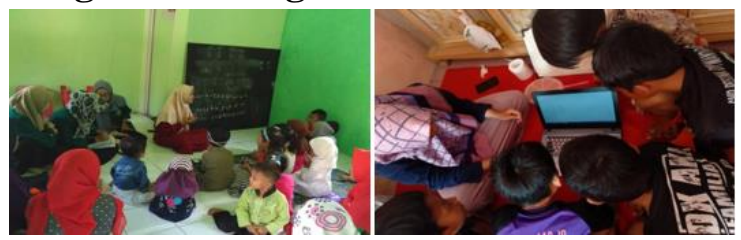

a. Sosialisasi ke PAUD

b. Bimbingan Belajar Komputer

\section{Program Bidang Keagamaan}

a. Mengajarkan anak- anak mengaji

\section{Program Bidang Teknik}

a. Membuat papan nama Gang/ Jalan 


\section{KESIMPULAN}

Berdasarkan penjelasan mengenai pelaksanaan program kerja KKN Universitas Ibn Khaldun Bogor tahun 2018. di lokasi RW 09 yang telah dilaksanakan pada tanggal 07 Agustus sampai tanggal 07 September 2018, maka dapt diambil beberapa kesimpulan sebagai berikut :

1. Kegiatan / program fisik dapat terlaksana dengan baik. Meskipun terdapat kendala dalam proses pelaksanaannya. Program ini dilaksanakan bersama-sama antara mahasiswa dengan masyarakat.

2. Kegiatan / program non fisik terlaksana dengan baik, program berupa penyadaran, pendampingan dan penyuluhan kepada masyarakat memerlukan proses yang cukup lama. Dari mulai sosialisasi sampai pelaksanaan. Target secara kualitas tercapai, namun secara kuantitas beberapa program masih kurang sesuai dengan harapan.

3. Mahasiswa memiliki pengalaman dalam bersosialisasi di masyarakat dan dapat mengenali berbagai karakter yang ada di lingkungan masyarakat.

\section{SARAN}

\section{Kepada Masyarakat}

a. Perlunya dukungan dari masyarakat terhadap berbagai program KKN yang dilaksanakan.

b. Masyarakat diharapkan dapat memberikan seluruh informasi yang diperlukan oleh mahasiswa KKN sehingga mahasiswa dapat membuat program sesuai dengan kebutuhan masyarakat.

c. Masyarakat harus menyadari bahwa KKN berfungsi sebagai motivator dan fasilitator, bukan sebagai penyandang dana.

\section{Untuk Pemerintah Daerah}

a. Dukungan pihak Pemerintah Daerah terhadap adanya mahasiswa KKN hendaknya ditingkatkan lagi dalam bentuk bantuan materil maupun non materiil.

b. Ada follow up (tindak lanjut) dari Pemerintahan Daerah Kota Bogor Barat terhadap beberapa programprogram KKN yang telah diselenggarakan berupa pendampingan. 


\section{REFERENSI}

\section{Buku Pedoman KKN UIKA}

Sujarweni . V . W. (2015). Metodologi

Penelitian Bisnis \& Ekonomi.

Yogyakarta : PT Pustaka Baru.

http://kecamatanleuwisadeng.bogorkab.go.id/i ndex.php/multisite/detail_desa/295

Adi Nugroho, ST, MMSI (2002). Analisis dan Perancangan Sistem informasi. Bansung: Informatika 